\title{
Heart failure in the elderly: A geriatric syndrome. Picture of the modern situation
}

\author{
Valentina Fagotto $^{1}$, Alessandro Cavarape ${ }^{1}$, Alessandro Boccanelli ${ }^{2}$ \\ ${ }^{1}$ Department of Experimental and Clinical Sciences, University of Udine; ${ }^{2}$ Department of Cardiocirculatory System, \\ San Giovanni-Addolorata-Britannico Hospital, Rome, Italy
}

\begin{abstract}
Among the older patients' cohort, the aetiology of heart failure is peculiar and differs in many ways from the younger one, both in its epidemiology, diagnostic work-up and clinical presentation. Focusing on this population, we could assume that heart failure is a real geriatric syndrome, characterized by several features, which coexist with other comorbidities and require specific and targeted cares. It is therefore necessary to examine the global burden of heart failure and the patient's history rather than the causal cardiomyopathy - frequently more than one in the elderly - facing with the condition, bearing in mind the quality of life even before its duration.
\end{abstract}

\section{Introduction}

Heart failure (HF) affects about the $16 \%$ of individuals 75 years of age and older, respect $4-5 \%$ of individuals 45 years and older [1], even with the limits due to different populations investigated and different criteria applied for the diagnosis of this disease.

Identifying a single condition determining alone HF in the elderly is pretty hard, while finding the main causes of HF in the general population is relatively easy (just citing the most frequent: ischaemic, hypertensive and heart valve disease-related) [2]. In geriatric cohorts, finding out several pathological events, concur-

\footnotetext{
Correspondence: Valentina Fagotto, Department of Experimental and Clinical Sciences, University of Udine, Via Monte Grappa 115, 33100 Udine, Italy.

Tel. +39.340.6438557.

E-mail: valentina.fagotto@icloud.com
}

Key words: Heart failure; geriatrics; aetiology of heart failure; elderly.

Received for publication: 4 January 2019.

Accepted for publication: 21 March 2019.

(C) Copyright V. Fagotto et al., 2019

Licensee PAGEPress, Italy

Monaldi Archives for Chest Disease 2019; 89:1031

doi: 10.4081/monaldi.2019.1031

This article is distributed under the terms of the Creative Commons Attribution Noncommercial License (by-nc 4.0) which permits any noncommercial use, distribution, and reproduction in any medium, provided the original author(s) and source are credited. rent to determine $\mathrm{HF}$, is rather common [3]. Here, factors as polypharmacy, malnutrition and cognitive impairment play a fundamental role that is often underestimated. We can state that HF in the elderly is a multifactorial condition.

\section{Current evidence}

Heart failure is more than ever a geriatric topic: we are currently spectators of a progressive increase of the mean age at the first diagnosis of HF, which at the time of writing is of 80 years. HF can be considered a "geriatric epidemic", partly because nowadays life expectation has been enormously elongated by early diagnosis and effective targeted therapies for several common diseases, which have also decreased the recurrence of acute events [4]. However, this has also led to the appearance of increasingly cases of chronic comorbidities.

\section{Pathophysiology}

Finding out an elderly patient affected by only a single cardiovascular disease that has led to HF is unexpected; there are more frequently various correlated conditions characterising a clinical status of HF. Furthermore, also typical and physiological ageing of cardiovascular system and vascular structures leads to HF (Table 1). From this point of view, HF is more like a physio-pathological condition than a pathological status derived from a defined disease.

The higher prevalence of HF in women and the higher number of preserved ejection fraction ( $\mathrm{pEF}$ ) are other points of interest which characterise this condition in older adults if compared with younger cohorts $[5,6]$. These findings are mainly due to the higher mean age and the lower incidence of ischaemic disease in females. If we could draw a model of the "typical old HF patient", it could be a woman of 85 years affected by hypertension and kidney impairment, not totally self-sufficient, with polypharmacy and low compliance to drug assumption and HFpEF.

In summary, we can conclude that the main features of HF as geriatric syndrome [7] are the following:

i. multifactorial aetiology;

ii. heterogeneity of presentation, with frequent overlaps between several co-existing morbidities;

iii. difficulty in the diagnostic work-up, mainly due to the impossibility to perform histological or instrumental tests and exams;

iv. chance to easily find out some aetiological indicators for certain risk factors; 
Table 1. Main microscopic alteration of the cardiovascular system due to physiological ageing.

\begin{tabular}{ll}
\hline Cardiomyocytes & Decrease in function and number \\
Calcium metabolism & Alteration that leads to contractility impairment \\
\hline Contractile proteins & Modification due to aging, with reduction in function and number \\
ATP use & Reduced efficacy \\
\hline Fibrosis & Increased \\
Extracellular matrix metabolism & Alteration in pro-fibrotic direction \\
\hline
\end{tabular}

ATP, adenosine triphosphate.

v. role of other comorbidities in determining a worse outcome.

vi. Due to these reasons, there is the need to face with HF in the elderly with a multidimensional approach, evaluating from the beginning not only the usual linear model "targeted diagnosis - targeted therapy" but rather the global frame, giving value to the quality of life, the residual autonomy level of the patient and the familiar and social support, considering the polypharmacy risks and the comorbidities burden in order to guarantee the best work-up for such a challenging and tricky condition.

\section{References}

1. Chivite D, Franco J, Formiga F. Chronic heart failure in the elderly patient. Rev Esp Geriatr Gerontol 2015;50:237-46.

2. Ponikowski P, Voors AA, Anker SD, et al. 2016 ESC Guidelines for the diagnosis and treatment of acute and chronic heart failure: The Task Force for the diagnosis and treatment of acute and chronic heart failure of the European Society of Cardiology (ESC). Developed with the special contribution of the Heart Failure Association (HFA) of the ESC. Eur J Heart Fail 2016;188:891-975.

3. Panjrath G, Ahmed A. Diagnosis and management of heart failure in older adults. Heart Fail Clin 2017;13:427-44.

4. Forman DE, Ahmed A, Fleg JL. Heart failure in very old adults. Curr Heart Fail Rep 2013;10:387-400.

5. Van Riet EE, Hoes AW, Wagenaar KP, et al. Epidemiology of heart failure: the prevalence of heart failure and ventricular dysfunction in older adults over time. A systematic review. Eur J Heart Fail 2016;18:242-52.

6. Páez-Rubio MI, Carrasco-Sánchez FJ, Escobar-Cervantes C, et al. Heart failure with preserved and reduced ejection fraction: different phenotypes in old-elderly patients? Eur J Intern Med 2013;24:346-8.

7. Inouye SK, Studenski S, Tinetti ME, et al. Geriatric syndromes: clinical, research and policy implications of a core geriatric concept. J Am Geriatr Soc 2007;55:781. 